\title{
Short-term comparison of the use of static and expandable intramedullary rods in the lower limbs of children with osteogenesis imperfecta
}

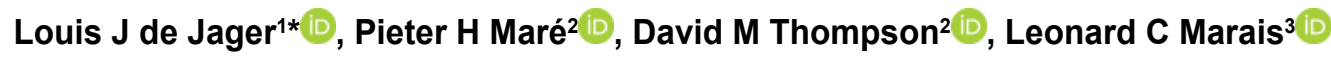 \\ 1 RK Khan Hospital, Nelson R Mandela School of Medicine, University of KwaZulu-Natal, Durban, South Africa \\ 2 Grey's Hospital, Nelson R Mandela School of Medicine, University of KwaZulu-Natal, Pietermaritzburg, South Africa \\ 3 Department of Orthopaedics, Nelson R Mandela School of Medicine, University of KwaZulu-Natal, Durban, South Africa \\ *Corresponding author: louisdejager2@gmail.com
}

Citation: De Jager LJ, Maré $\mathrm{PH}$, Thompson DM, Marais LC. Short-term comparison of the use of static and expandable intramedullary rods in the lower limbs of children with osteogenesis imperfecta. SA Orthop J 2021;20(1):27-32. http://dx.doi.org/10.17159/23098309/2021/v20n1a3

Editor: Dr Greg Firth, London, England

Received: July 2020

Accepted: October 2020

Published: March 2021

Copyright: @ 2021 De Jager LJ. This is an open-access article distributed under the terms of the Creative Commons Attribution Licence, which permits unrestricted use, distribution and reproduction in any medium, provided the original author and source are credited.

Funding: No funding was received for this study.

Conflict of interest: The authors declare they have no conflicts of interest that are directly or indirectly related to the research.

\begin{abstract}
\section{Background}

Children with osteogenesis imperfecta suffer from frequent fractures and deformities due to skeletal fragility. Stabilisation of fractures, correction of deformity and intramedullary rodding result in decreased pain and improved function. Modern expandable intramedullary rods aim to provide lasting stability during growth, without an increase in complications. The aim of our study was to determine and compare the outcome of static Rush rods and expandable Fassier-Duval rods in terms of complications and reoperation rate.
\end{abstract}

\section{Methods}

We reviewed the records of a cohort of 17 children (seven female) with osteogenesis imperfecta (11 Sillence type III, six Sillence type IV) who were treated with intramedullary rods in the lower limb between 2011 and 2017. They had 64 rodding (38 femoral and 26 tibial) procedures (26 Rush rods and 38 Fassier-Duval rods). These were a primary procedure in 46 , and a revision procedure after previous Rush rodding in 18 cases.

\section{Results}

The overall complication rate was $66 \%(n=42)$. There was a higher complication rate in the Rush rod group $(81 \%, n=21)$ when compared to the Fassier-Duval group $(55 \%, n=21)(p=0.035)$. The most frequent complication in the Rush rod group was distal deformity as the rod is outgrown $(69 \%, n=18)$. The most frequent complication in the Fassier-Duval rod group was intramedullary migration due to a failure to expand $(45 \%, n=17)$. Factors that were associated with increased risk of complications included younger age $(p=0.031)$, type of rod $(p=0.035)$, and deformity as an indication for surgery $(77 \%$ complications, $p=0.033)$. At a mean follow-up of 3.1 years, the reoperation rate in the Rush rod group was $58 \%(n=15)$. Comparatively, at a mean of 3.7 years follow-up, there were no reoperations in the Fassier-Duval group.

\section{Conclusions}

Despite the numerous innovations, the surgical management of lower limb deformities and fractures in children with osteogenesis imperfecta remains challenging with a relatively high complication rate. The use of Fassier-Duval rods may result in a lower reoperation rate when compared to Rush rods, in the short term.

Level of evidence: Level 4

Keywords: osteogenesis imperfecta, intramedullary rod, Rush rod, Fassier-Duval rod, fracture, deformity 


\section{Introduction}

Osteogenesis imperfecta $(\mathrm{OI})$ is a rare disorder characterised by a spectrum of skeletal fragility and associated features due to collagen abnormality. Children who are affected commonly present with progressive long bone deformities or fractures. Surgical interventions in these patients are challenging due to the combination of poor bone quality and severity of deformity. Several studies have shown a high rate of complications and reoperations associated with surgery. ${ }^{1-5}$

Surgery typically involves deformity correction and/or fracture fixation using either static or expandable intramedullary rods. ${ }^{6-8}$ Intramedullary rodding in children with severe OI has been shown to prevent pain, fractures and deformity. ${ }^{6}$ When combined with bisphosphonates, intramedullary rod fixation results in improved ambulation, gross motor function, self-care and mobility. ${ }^{9}$ Static and expandable rods share some of the same risks: external rod migration, infection, physeal injury, rod breakage and rotational malunion. Expandable rods have the potential benefit of lengthening as the patient grows. While this potentially reduces the risk of subsequent fracture or deformity, the use of these expandable rods can be associated with certain design-specific complications. These include failure to expand due to epiphyseal fixation failure and intra-articular penetration. ${ }^{2,8}$

The use of expandable rods results in a longer interval before reoperation is required (from 2-2.5 years to $4-5$ years). ${ }^{2,6,10,11}$ While the complication rates of expandable rods remain high, this has decreased with advances in implant design. Reported complication rates of the Fassier-Duval (FD) rod (Pega Medical, Quebec, Canada) are lower than those of earlier implants. ${ }^{7,9}$ There are few reports describing the surgical management of $\mathrm{Ol}$ from South Africa. ${ }^{3,12}$ Oduah et al. described the results of surgery using static rods without a comparative analysis. ${ }^{3}$ We see a high proportion of children who are severely affected, and our practice has included both the use of expandable and static intramedullary rods.

The aim of this study was to determine and compare the reoperation and complication rates of static Rush rods (RR) and expandable FD rods in the treatment of lower limb long bone fracture and deformity in children with OI.

\section{Materials and methods}

Non-probability purposive sampling was used to identify a cohort of 17 consecutive patients (64 cases) with OI under the age of 18 years who had intramedullary rod fixation (expandable or rigid) for the treatment of lower limb long bone fracture or deformity at our tertiary paediatric orthopaedic unit between November 2011 and December 2017. All OI patients younger than 18 years who received surgical treatment of a lower limb fracture or deformity were included. Cases with less than 12-month follow-up, or that required plate or locked nail intramedullary nail fixation, were excluded. Each surgical procedure was regarded as a separate case. If a previously operated limb segment required revision surgery, this was recorded as a new case and the indication for surgery recorded as a revision. Follow-up was calculated from the date of the procedure for all cases and thus all revision cases were handled as new cases. Reoperation was defined as the need for repeat surgery in each case.

Following ethical approval, clinical data was extracted from the paediatric orthopaedic database, together with the radiological records stored in our picture archiving and communication system (PACS). Data points included type of OI (according to the Sillence classification system), sex, mobility, age at surgery, site, indication for surgery, rod type, rod diameter, follow-up period, complications and whether reoperation was performed. Reoperation and complications were the primary outcome variables. Possible complications included infection, growth arrest, periprosthetic fracture, rod breakage, rod bending, transcortical rod migration, migration due to limited expansion and deformity $\left(>10^{\circ}\right)$ adjacent to an outgrown rod. Reoperation was defined as an unplanned repeat surgical event necessary to obtain the goals of the index procedure or to prevent a secondary disorder.

\section{Treatment strategy}

The surgical technique of deformity correction and intramedullary rod placement followed the description by Sofield and Fassier.6,13 The tibia and femur on one side were operated in the same setting when multiple rods were required. The decision whether to use static (RR) or expandable (FD) intramedullary rods was based on an estimation of the rod size required and growth remaining. We preferred RRs when $3.2 \mathrm{~mm}$ diameter or smaller rods were required (although we did insert two $3.2 \mathrm{~mm}$ FD rods). This was due to the high likelihood that rod revision would be required in younger children and that the revision of RRs was likely to be simpler. If less than two years of growth remained RRs were favoured as well, as revision was unlikely to be necessary in these cases and RRs were significantly more cost effective. The diameter of the FD rods ranged from $3.2 \mathrm{~mm}$ to $5.6 \mathrm{~mm}(3.2,4,4.8$ and $5.6 \mathrm{~mm})$. The diameter of RRs was either 3.2 or $4.8 \mathrm{~mm}$ (we did not have $4 \mathrm{~mm}$ RRs available). Intravenous zoledronic acid $(0.05 \mathrm{mg} / \mathrm{kg}$ diluted in normal saline) was given as an infusion over 30 minutes after oral calcium supplementation at six-monthly intervals at our Metabolic Bone Clinic.

\section{Statistical analysis}

Statistical analysis was performed using Stata 15.0 (StataCorp. College Station, Texas). Continuous variables were reported as mean ( \pm standard deviation [SD] and ranges) and categorical variables as number and percentages. The primary dependent outcome variables were complication and reoperation. The Shapiro-Wilk test was used to analyse the distribution of data. Normally distributed data (age, follow-up duration) were compared with the use of the unpaired t-test, whereas the Wilcoxon rank-sum test was used for non-parametric data (rod diameter). Categorical data (sex, OI type, rod type, surgical indication) were compared using the Fisher's exact test if the expected value in any cell was below 5 , or alternatively the Pearson's chi-squared test. All tests were two-sided and the level of significance was set at $p<0.05$.

\section{Results}

The study cohort included 17 patients (seven females). Two femoral RRs were revised to locked intramedullary nails and excluded from further analysis. One case was excluded due to a follow-up duration of less than 12 months. This left us with 64 cases (rodding procedures) that were included in the analysis. The breakdown per segment was as follows: nine patients required rodding of all four lower limb segments, six patients of bilateral femurs, one patient of three segments (bilateral tibias and one femur) and one patient a single femur. There were $46(72 \%)$ primary procedures and $18(28 \%)$ revision procedures (15 FD rods and three RRs were inserted at revision surgery). Of the 18 procedures that were revisions, 13 were done following RRs that were also included in our series as new FD cases. The other five revisions were required following RRs that were done elsewhere before presenting to our unit and the original procedures were not included in our series as primary cases. 
Table I: Summary of the descriptive characteristics of our patients

\begin{tabular}{|c|c|c|c|c|}
\hline Measurement & n (\%) & $\begin{array}{c}\text { Mean } \\
\text { (years) }\end{array}$ & SD & Range \\
\hline Patients & 17 & & & \\
\hline Procedures & 64 & & & \\
\hline Male & $44(69 \%)$ & 6.6 & 3.1 & $2-14$ \\
\hline Female & $20(31 \%)$ & 7.6 & 3.1 & $4-16$ \\
\hline Age (years) & 64 & 6.9 & 3.0 & $2-16$ \\
\hline \multicolumn{5}{|l|}{ Sillence type } \\
\hline Type III & $11(65 \%)$ & & & \\
\hline Type IV & $6(35 \%)$ & & & \\
\hline \multicolumn{5}{|l|}{ Rush rods } \\
\hline Age at surgery (years) & 26 & 6.6 & 3.7 & $2-16$ \\
\hline Follow-up & 26 & 3.1 & 1.4 & $1.3-4.8$ \\
\hline Complication rate & $21(81 \%)$ & & & \\
\hline Outgrown rod with deformity & $18(69 \%)$ & & & \\
\hline Outgrown rod with fracture & $1(4 \%)$ & & & \\
\hline Fractured rod and femur & $1(4 \%)$ & & & \\
\hline Proximal migration & $1(4 \%)$ & & & \\
\hline Reoperation rate & $15(58 \%)$ & & & \\
\hline \multicolumn{5}{|l|}{ Fassier-Duval rods } \\
\hline Age at surgery & 38 & 7.1 & 2.5 & $2-11$ \\
\hline Follow-up & 38 & 3.7 & 1.5 & $1-6.4$ \\
\hline Complication rate & $21(55 \%)$ & & & \\
\hline Failure to expand & $17(45 \%)$ & & & \\
\hline Joint penetration & $3(8 \%)$ & & & \\
\hline Proximal cut-out & $1(3 \%)$ & & & \\
\hline Reoperation rate & $0(0 \%)$ & & & \\
\hline
\end{tabular}

Descriptive data are summarised in Table $I$. The mean age at surgery was 6.9 years. There were 26 RRs and 38 FD rods inserted during the study period. More femoral $(59 \%, n=38)$ than tibial $(41 \%, n=26)$ rods were inserted. The indications for surgical procedure were deformity correction $(55 \%, 35 / 64)$, stabilisation of fractures $(17 \%, 11 / 64)$ and revision surgery for complications after a previous RR procedure $(28 \%, 18 / 64)$. These complications were mostly recurrent deformity when the rod was outgrown (17/18), and one case of proximal rod migration. The mean follow-up was 3.6 years (standard deviation [SD] 1.5, range 1 to 6.4 years).

A comparison of descriptive data between the RR and the FD rod group is summarised in Table II. There was no difference between the two groups in terms of age, sex, type of Ol, site (tibia or femur), or follow-up duration. While the number of cases performed for fractures and deformities was comparable, there were more revision procedures performed in the FD group ( $40 \%$ vs $12 \%, p=0.022$ )

The complication rate in the RR group was $81 \%(n=21)$. The most common complication $(69 \%, n=18)$ was distal deformity when the rod was outgrown (Figure 1). In addition, there was one fracture of the rod and femur, one tibia fracture distal to an outgrown rod, and one case of proximal migration into the gluteal region of an RR in the femur. The reoperation rate for RRs during the study period was $58 \%(n=15)$. The mean time to reoperation was 22 months (SD 9 months, range 1-36 months).

The complication rate in the FD group was $55 \% \quad(n=21)$. The most common complication $(45 \%, n=17)$ was limited rod expansion (Figure 2), associated with a bent rod in $41 \%(n=7$, four
Table II: Descriptive data reported for the Rush rod and Fassier-Duval (FD) rod groups

\begin{tabular}{|c|c|c|c|}
\hline Variable & $\begin{array}{c}\text { Rush rod } \\
n=26(41 \%)\end{array}$ & $\begin{array}{c}\text { FD rod } \\
n=38(59 \%)\end{array}$ & p-value \\
\hline Age (mean years $\pm S D$ ) & $6.6 \pm 3.7$ & $7.1 \pm 2.5$ & 0.149 \\
\hline \multicolumn{4}{|l|}{$\operatorname{Sex}$} \\
\hline Male & $19(73 \%)$ & $25(38 \%)$ & 0.537 \\
\hline \multicolumn{4}{|l|}{ Sillence classification } \\
\hline Type III & $19(46 \%)$ & $22(54 \%)$ & \multirow{2}{*}{0.214} \\
\hline Type IV & $7(30 \%)$ & $16(70 \%)$ & \\
\hline \multicolumn{4}{|l|}{ Location } \\
\hline Femur & $13(50 \%)$ & $25(66 \%)$ & \multirow{2}{*}{0.207} \\
\hline Tibia & $13(50 \%)$ & $13(34 \%)$ & \\
\hline \multicolumn{4}{|l|}{ Indication for surgery } \\
\hline Deformity & $17(65 \%)$ & $18(47 \%)$ & 0.155 \\
\hline Fracture & $6(23 \%)$ & $5(13 \%)$ & 0.331 \\
\hline Revision & $3(12 \%)$ & $15(40 \%)$ & 0.022 \\
\hline \multicolumn{4}{|l|}{ Implant size } \\
\hline Rod diameter & $3.9 \pm 0.1$ & $4.7 \pm 0.6$ & $<0.001$ \\
\hline Follow-up (mean years $\pm S D$ ) & $3.1 \pm 1.4$ & $3.7 \pm 1.5$ & 0.246 \\
\hline
\end{tabular}

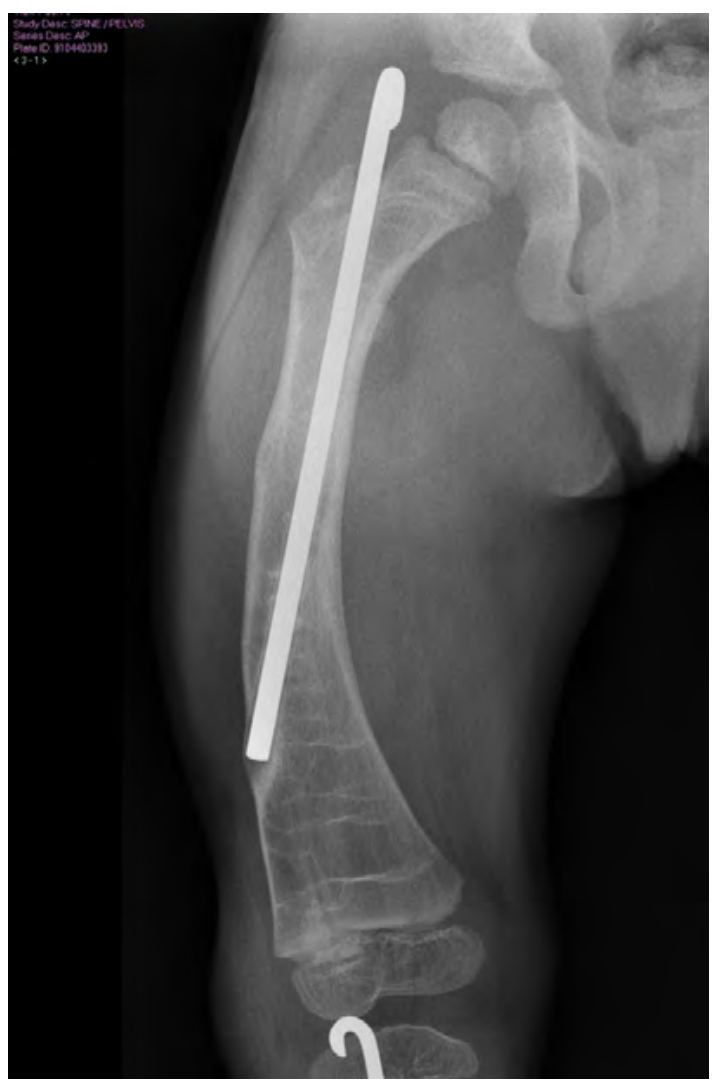

Figure 1. AP radiograph of the right femur of a 6-year-old boy. The rod is outgrown, and distal deformity is evident.

femurs and three tibia) of cases. There were three instances (8\%) of distal articular penetration of the obturator segment of the FD rod (two involving the ankle joint and one the knee). The articular penetration in the ankles were both in a patient with small, distorted distal tibial epiphysis. She was wheelchair-bound pre-operatively and asymptomatic post-operatively, and replacement of the rod 


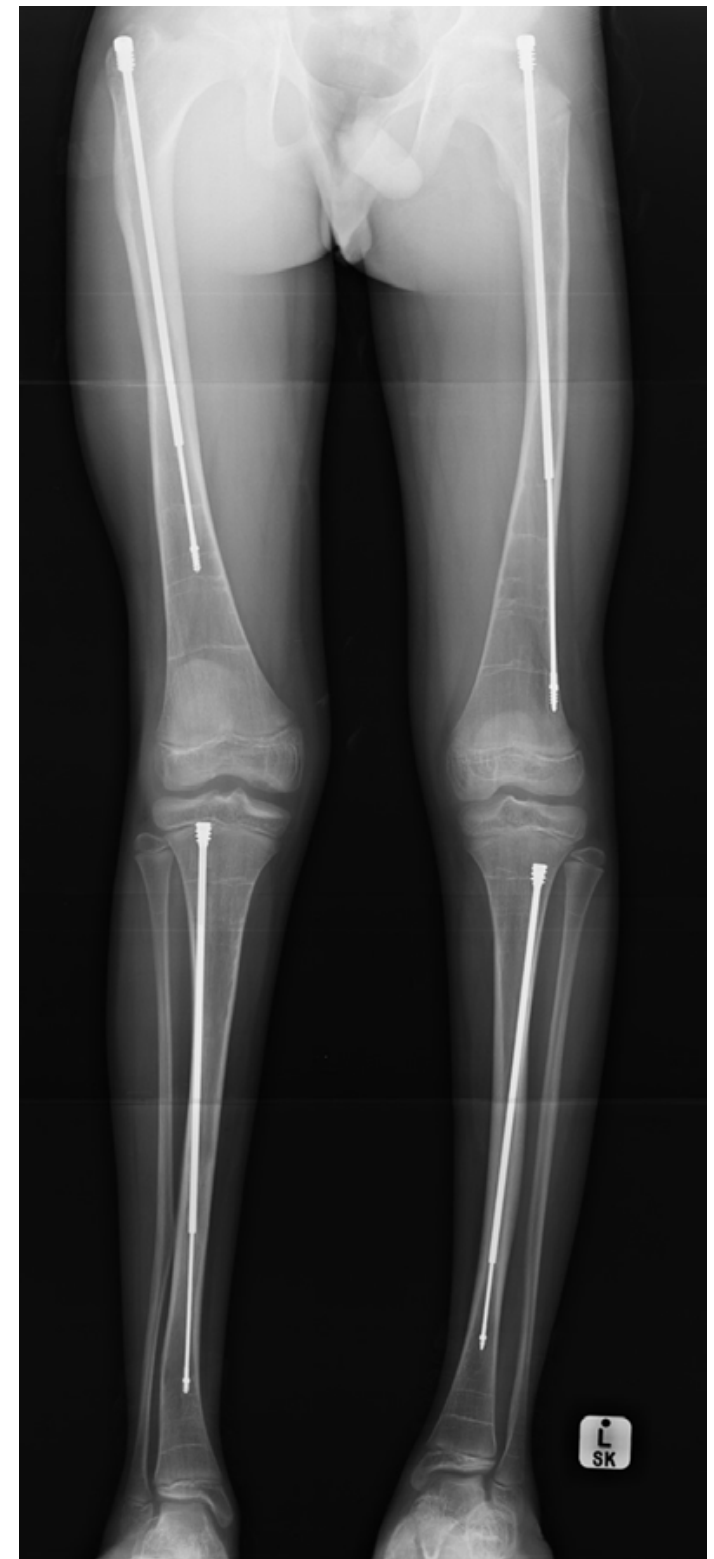

Figure 2. Standing AP radiograph of a 12-year-old boy six years after deformity correction and Fassier-Duval rod insertion. Limited expansion is present in all four rods with proximal migration of the obturator segment. Distal migration of the sleeve segment is present only in the tibial rods.

was not attempted. The articular penetration in the knee was also asymptomatic and, as it subsequently moved to a subcortical position during growth, did not require revision. In another case a subtrochanteric proximal femur stress fracture, with an FD rod in situ, resulted in varus deformity with proximal lateral transcortical migration. She was asymptomatic and declined further surgery (Figure 3). There was no case of infection or growth arrest observed. There were no reoperations in the FD rod group.

Comparative data relating to the development of complications are described in Table III. Factors that were associated with increased risk of complications included younger age (mean age $6.3 \pm 3$ vs $8 \pm 3.1$ years, $p=0.031$ ), type of rod (RR $81 \%$ vs FD rod $54 \%, p=0.035)$, and deformity as an indication for surgery $(77 \%$ complications, $p=0.033$ ).

Comparative data relating to the need for reoperation is described in Table IV. Male sex correlated with an increased risk of reoperation (male $32 \%$, female $5 \%, p=0.025$ ). We could not detect any confounders in terms of severity of OI, age at surgery, indication or implant choice that could explain this. Revision

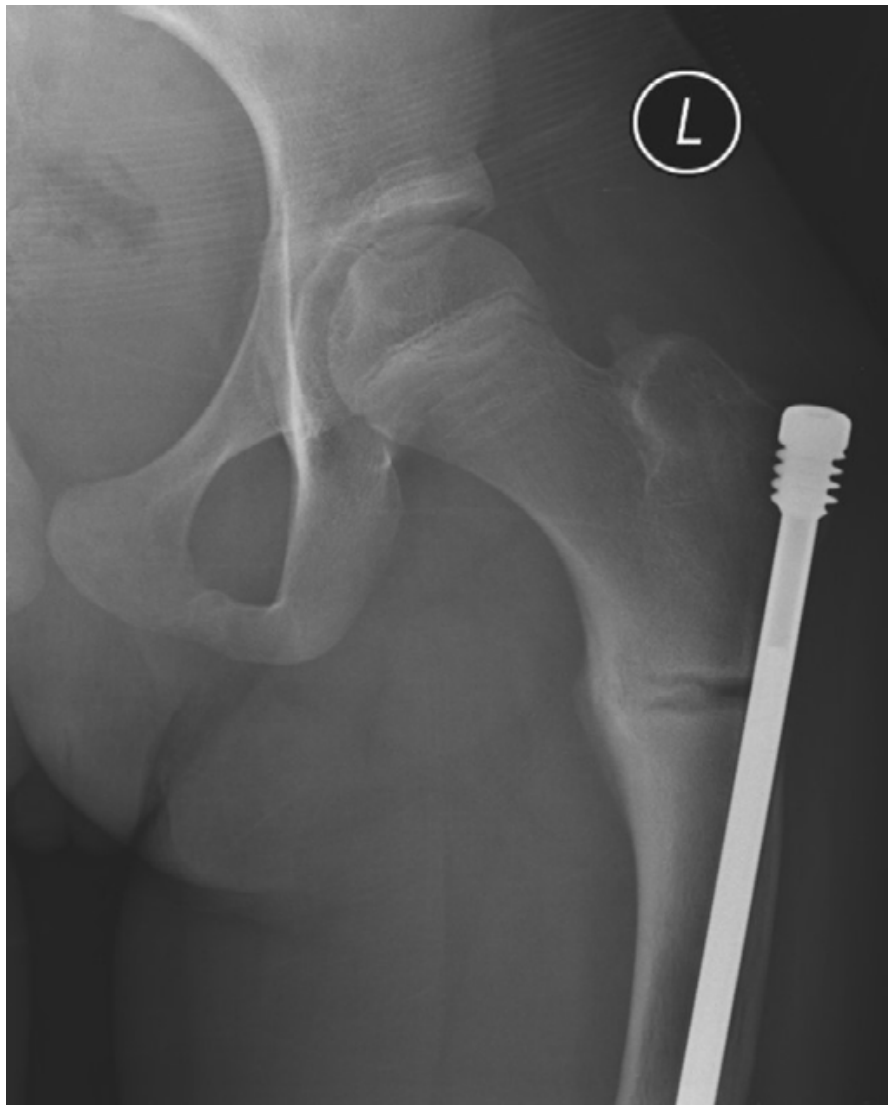

Figure 3. AP radiograph of the left hip and proximal femur in a 12-year-old girl. Lateral transcortical migration of the proximal Fassier-Duval rod due to a subtrochanteric proximal femur stress fracture and varus deformity is evident.

Table III: Comparative data related to the development of complications

\begin{tabular}{|l|c|c|c|}
\hline \multicolumn{1}{|c|}{ Variable } & $\begin{array}{c}\text { No } \\
\text { complication }\end{array}$ & Complication & p-value \\
\hline Age (mean years \pm SD) & $8 \pm 3.1$ & $6.3 \pm 3.0$ & 0.031 \\
\hline Sex & & & \\
\hline Male & $14(32 \%)$ & $30(68 \%)$ & 0.523 \\
\hline Female & $8(40 \%)$ & $12(60 \%)$ & \\
\hline Sillence type & $15(36 \%)$ & $26(64 \%)$ & 0.619 \\
\hline Type III & $7(30 \%)$ & $16(70 \%)$ & \\
\hline Type IV & & & \\
\hline Location & $14(37 \%)$ & $24(63 \%)$ & 0.615 \\
\hline Femur & $8(31 \%)$ & $18(69 \%)$ & \\
\hline Tibia & & & 0.033 \\
\hline Indication for surgery & $8(23 \%)$ & $27(77 \%)$ & 0.166 \\
\hline Deformity & $6(55 \%)$ & $5(45 \%)$ & 0.289 \\
\hline Fracture & $8(44 \%)$ & $10(66 \%)$ & \\
\hline Revision & & & \\
\hline Implant & $5(19 \%)$ & $21(81 \%)$ & $\mathbf{0 . 0 3 5}$ \\
\hline Rush rod & $17(46 \%)$ & $21(54 \%)$ & \\
\hline Fassier-Duval rod & & $4.2 \pm 0.78$ & 0.116 \\
\hline Implant size & $4.5 \pm 0.70$ & $4.0 \pm 0.82$ & 0.280 \\
\hline Rod diameter & $3.5 \pm 0.71$ & $4.5 \pm 0.64$ & 0.053 \\
\hline Rush rod diameter & $4.8 \pm 0.33$ & \\
\hline Fassier-Duval diameter & & \\
\hline
\end{tabular}


Table IV: Comparative data relating to the need for a reoperation

\begin{tabular}{|l|c|c|c|}
\hline \multicolumn{1}{|c|}{ Variable } & No reoperation & Reoperation & p-value \\
\hline Age (mean years \pm SD) & $7.1 \pm 2.85$ & $6.27 \pm 3.73$ & 0.361 \\
\hline Sex & & & \\
\hline Male & $30(68 \%)$ & $14(32 \%)$ & 0.025 \\
\hline Female & $19(95 \%)$ & $1(5 \%)$ & \\
\hline Sillence type & & & \\
\hline Type III & $31(76 \%)$ & $10(24 \%)$ & 0.810 \\
\hline Type IV & $18(78 \%)$ & $5(22 \%)$ & \\
\hline Location & & & \\
\hline Femur & $29(74 \%)$ & $9(26 \%)$ & 1.000 \\
\hline Tibia & $20(77 \%)$ & $6(23 \%)$ & \\
\hline Indication for surgery & & $10(24 \%)$ & 1.000 \\
\hline Deformity & $31(76 \%)$ & $4(36 \%)$ & 0.268 \\
\hline Fracture & $7(64 \%)$ & $1(6 \%)$ & $\mathbf{0 . 0 4 8}$ \\
\hline Revision & $17(94 \%)$ & & \\
\hline Implant & & $15(58 \%)$ & $<0.001$ \\
\hline Rush rod & $11(42 \%)$ & $0(0 \%)$ & \\
\hline Fassier-Duval rod & $38(100 \%)$ & $3.8 \pm 0.81$ & $\mathbf{0 . 0 0 7}$ \\
\hline Implant size & & & \\
\hline Diameter & $4.5 \pm 0.69$ & & \\
\hline
\end{tabular}

procedures had a lower risk of subsequent reoperation (6\% vs $30 \%$ in primary cases). Other variables that were associated with a decreased need for reoperation included larger implant diameter $(p=0.007)$ and the type of rod (RR $58 \%$ vs FD rod $0 \%, p<0.001)$.

\section{Discussion}

The surgical management of long bone deformities and fractures in OI was pioneered by Sofield and Millar in 1959. ${ }^{6}$ They described deformity correction through multilevel osteotomies along with intramedullary rod fixation. The static rods protected the long bone from deformity and refracture in the post-operative period. With subsequent growth, however, the segments distal or proximal to the rods were prone to deformity or fracture, necessitating reoperation. This led to the invention of expandable (or telescoping) rods, designed by Bailey and Dubow. ${ }^{7}$ These rods could potentially delay reoperation when compared to solid rods but added complexity and had their own unique set of complications. ${ }^{2}$ Specifically, the T-piece that provided epiphyseal fixation was susceptible to articular displacement. The Sheffield rod, where the T-piece was fixed, reduced the risk of displacement. ${ }^{7}$ The FD rod was the first single entry expandable rod system, preventing the need for distal arthrotomy during insertion. ${ }^{8}$ The FD rod has threaded epiphyseal portions on both the obturator and sleeve sections that stabilise the rod during expansion with growth. While the system allows for epiphyseal locking of the obturator segment, we did not utilise this option. Short-term follow-up of this device reports a reoperation rate of $13 \% .^{8}$

The aim of our study was to determine and compare the complication and reoperation rates in a cohort of children treated with static and elongating intramedullary rods for lower limb deformities and fractures due to $O$ I.

Our patient cohort consisted of children with Sillence type III and IV in similar proportions to other studies that reported the surgical outcomes in children with Ol.3,11,14 The mean age at initial surgery (6.9 years), similarly, is comparable to that of other reports on the subject. $2,3,14$
During the study period there was a higher complication rate in the RR group (81\%) when compared to the FD rod group (55\%) $(p=0.035)$. This confirms the findings of previous studies showing higher complication rates with the use of static rods. ${ }^{2,9,15-17}$ The main complication in the RR group was distal deformity, which occurred when the rod was outgrown ( $86 \%$ of complications in this group). This occurred despite bisphosphonate therapy. Our complications in the FD rod group consisted mainly of rods that failed to expand with growth $(45 \%, n=17)$. In comparison, expansion failure was reported in $33 \%(n=5)$ by Birke et al., and in $16 \%(n=28)$ of cases by Azzam et al. 8,11 Lee et al. reported a $32 \%(n=13)$ failure rate due to rod bending in $41 \mathrm{FD}$ rods. The mean time to rod bending was 4.0 years (range $0.9-8.2$ years). ${ }^{17}$ We confirmed this mode of failure, as we found that $41 \%(n=7)$ of the 17 rods that failed to expand had bent. Transcortical migration due to proximal femur deformity, normally described in RRs with progressive deformity, occurred with one FD rod after initial central placement subsequent to proximal femur stress fracture..$^{2}$ Intra-articular penetration of the obturator segment of FD rods has previously been reported. ${ }^{8,11}$ This occurred in three cases in our series. Birke et al. described a combined insertion technique to prevent articular penetration where bone quality is poor and the epiphysis is narrow and distorted, which might be useful in selected cases. ${ }^{8}$ We found that children who developed complications were operated at a younger age ( 6.3 vs 8 years, $p=0.031$ ). Previous authors have also noted this association. ${ }^{1,3}$

During our study period, with a mean follow-up of 3.6 years, there had been no reoperations in the FD group. Contrastingly, the reoperation rate was $58 \%$ in the RR group, with a mean time to revision of 22 months. The expected time to reoperation after deformity correction and static intramedullary rod fixation is 2-2.5 years. ${ }^{6}$ Expandable rods are expected to delay this interval to 4-5 years. $^{2,10}$ Initial studies on FD rods reported a reoperation rate of $13-14 \%$ at short-term follow-up..$^{8,9}$ Azzam et al. reported a reoperation rate of $46 \%$ at a mean 4.3 years in a large cohort of 179 lower extremity FD rods. ${ }^{11}$ Most recently, Spahn et al. reported a higher probability of survival for FD rods when compared to static rods over the first 48 months $(88.1 \%$ [95\% Cl 68-96\%] vs $41 \%$ [95\% Cl 25-56\%]). ${ }^{14}$ Our results corroborate the expected improved survival of FD rods in comparison to RRs. Despite the high rate of limited expansion seen in the FD rod group, there was still a lower reoperation rate when compared to the RR group.

There are several limitations to our study. Our indications for whether to use a static or expandable rod predisposed the study to selection bias. Despite this, our study groups were comparable in terms of type of OI, age at operation, site and follow-up duration. Documentation of mobility and functional status prior to surgery and at the end of the study period was incomplete, limiting our ability to evaluate the combined effect of intramedullary rodding and bisphosphonate therapy. While longer follow-up would have shed light on the expected survival of FD rods, we were able to confirm the short-term difference in reoperation rate between RRs and FD rods. With ongoing follow-up, monitoring of reoperations will enable us to calculate the survival rate of the FD rods in our study group. The small sample size prohibited the development of a regression model to identify factors associated with complications. A larger prospective series is required to shed further light on the subject.

\section{Conclusion}

Despite the numerous innovations, the surgical management of lower limb deformities and fractures in children with OI remains challenging. The complication rates of intramedullary rods are relatively high. The most common complication of RRs was 
deformity at the distal end of the rod during growth, which frequently necessitated reoperation. The most common complication of FD rods was failure to expand during growth. Despite this complication, the use of FD rods may result in a lower reoperation rate when compared to RRs in the short term.

\section{Ethics statement}

Ethics approval was obtained from the Biomedical Research Ethics Committee (BCA268-15)

The authors declare that this submission is in accordance with the principles laid down by the Responsible Research Publication Position Statements as developed at the 2nd World Conference on Research Integrity in Singapore, 2010. All procedures were in accordance with the ethical standards of the responsible committee on human experimentation (institutional and national) and with the Helsinki Declaration of 1975 as revised in 2008. Informed written consent was not required for inclusion in the study.

\section{Declaration}

The authors declare authorship of this article and that they have followed sound scientific research practice. This research is original and does not transgress plagiarism policies.

\section{Author contributions}

LJJ: Study design, data collection, manuscript preparation

PHM: Study design, data collection, statistical analysis, manuscript review

DMT: Study design, manuscript review

LCM: Study design, statistical analysis, manuscript review

\section{References}

1. Zionts LE, Ebramzadeh E, Stott SN. Complications in the use of the BaileyDubow extensible nail. Clin Orthop Rel Res. 1998;348:186-95.

2. Luhmann SJ, Sheridan JJ, Capelli AM, et al. Management of lower-extremity deformities in osteogenesis imperfecta with extensible intramedullary rod technique: A 20-year experience. J Pediatr Orthop. 1998;18(1):88-94.

3. Oduah GO, Firth GB, Pettifor JM, et al. Management of osteogenesis imperfecta at the Chris Hani Baragwanath Hospital. S Afr Orthop J. 2017;16(2):19-25

4. Scollan JP, Jauregui JJ, Jacobsen CM, et al. The outcomes of non-elongating intramedullary fixation of the lower extremity for pediatric osteogenesis imperfecta patients. J Pediatr Orthop 2017;37(5):313-16.

5. Zeitlin L, Fassier F, Glorieux FH. Modern approach to children with osteogenesis imperfecta. J Pediatr Orthop B. 2003;10:77-87.

6. Sofield HA, Millar EA. Fragmentation, realignment and intramedullary rod fixation of deformities of the long bones in children. A ten-year appraisal. J Bone Joint Surg. 1959;41-A(8):1371-91.

7. Burnei G, Vlad C, Stefan I, et al. Osteogenesis imperfecta: diagnosis and treatment. J Am Acad Orthop Surg. 2008;16:356-66.

8. Birke O, Davies $\mathrm{N}$, Latimer $\mathrm{M}$, et al. Experience with the telescopic rod: first 24 consecutive cases with a minimum of 1 year follow up. J Pediatr Orthop. 2011;31(4):458-64.

9. Ruck J, Dahan-Oliel N, Montpetit K, et al. Fassier-Duval rodding in children with osteogenesis imperfecta receiving bisphosphonates: functional outcomes at one year. J Child Orthop. 2011;5:217-24.

10. Joseph B, Rebello G, Kant CB. The choice of intramedullary devices for the femur and the tibia in osteogenesis imperfecta. J Pediatr Orthop B. 2005; $14: 311-19$

11. Azzam KA, Rush ET, Burke BR, et al. Mid-term results of femoral and tibial osteotomies and Fassier-Duval nailing in children with osteogenesis imperfecta. J Pediatr Orthop. 2018;38:331-36.

12. Robertson A, George A. A surgical technique for coxa vara in osteogenesis imperfecta. S Afr Orthop J. 2005;4(1):16-18.

13. Fassier F. Fassier-Duval telescopic system: How I do it? J Pediatr Orthop. 2017;37(6):S48-S51.

14. Spahn KM, Mickel T, Carry PM, et al. Fassier-Duval rods are associated with superior probability of survival compared with static implants in a cohort of children with osteogenesis imperfecta deformities. J Pediatr Orthop. 2019;39:e392-e396.

15. Harrison W, Rankin C. Osteogenesis imperfecta in Zimbabwe: A comparison between treatment with intramedullary rods of fixed-length and self-expanding rods. J R Coll Surg Edinb.1998;43:328-32.

16. El-Adl G, Khalil MA, Enan A, et al. Telescoping versus non-telescoping rods in the treatment of osteogenesis imperfecta. Acta Orthop Belg. 2009;72(2):200-208.

17. Lee RJ, Paloski MD, Sponseller PD, et al. Bent telescopic rods in patients with osteogenesis imperfecta. J Pediatr Orthop. 2016;36(6):656-60. 